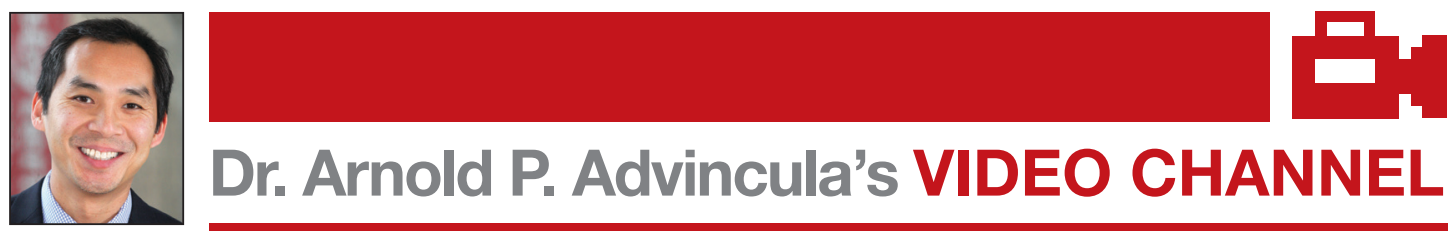

\title{
Isthmocele repair: Simultaneous hysteroscopy and robotic-assisted laparoscopy
}

\author{
Sierra J. Seaman, MD; Chetna Arora, MD; and Arnold P. Advincula, MD
}

\section{A} $\mathrm{n}$ isthmocele is a pouch-like anterior uterine wall defect at the site of a previous cesarean scar. The incidence is not well known, but it is estimated in the literature to be between $19 \%$ and $88 \%{ }^{1}$ Issues arising from an isthmocele may include abnormal uterine bleeding; abdominal pain; diminished fertility; ectopic pregnancy; or obstetric complications, such as uterine rupture. Repair of an isthmocele may be indicated for symptomatic relief and preservation of fertility. Multiple surgical approaches have been described in the literature, including laparoscopic, hysteroscopic, and vaginal approaches.

The objective of this video is to illustrate the use of robotic-assisted laparoscopy with simultaneous hysteroscopy as a feasible and safe approach for the repair of an isthmocele. Here we illustrate the key surgical steps of this approach, including:

1. presurgical planning with magnetic resonance imaging

2. diagnostic hysteroscopy for confirmation of isthmocele

3. simultaneous laparoscopy for identification of borders

4. strategic hysterotomy

5. excision of scar tissue

6. imbricated, tension-free closure.

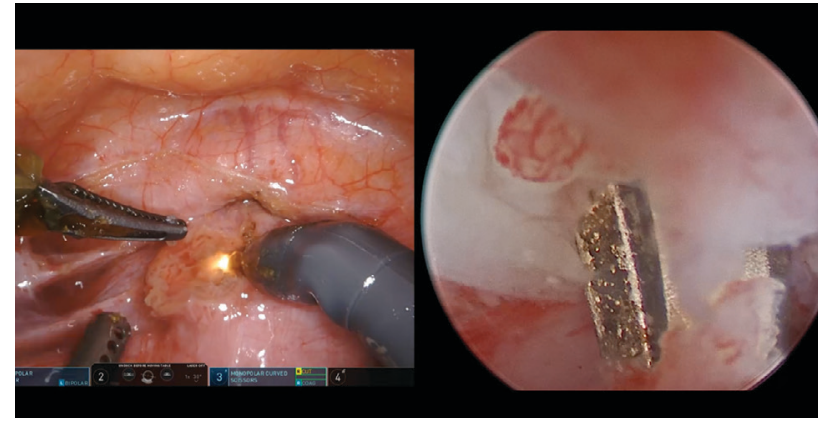

Exploration of the isthmocele with simultaneous robotic-assisted laparoscopy (left) and hysteroscopy (right).

\section{To view the video}

Visit Arnold Advincula's Surgical Techniques Video Channel in the Multimedia Library at mdedge.com/obgyn

We hope that you find this video useful to your clinical practice.

》) DR. ARNOLD P. ADVINCULA AND COLLEAGUES

\footnotetext{
Reference

1. Tower AM, Frishman GN. Cesarean scar defects: an underrecognized cause of abnormal uterine bleeding and other gynecologic complications. J Minim
} Invasive Gynecol. 2013;20:562-572. doi: 10.1016/j.jmig.2013.03.008.

Dr. Seaman is Resident, Division of Gynecologic Specialty Surgery, Department of Obstetrics and Gynecology, Columbia University Irving Medical Center/ New York-Presbyterian Hospital, New York.

Dr. Arora is Fellow, Division of Gynecologic Specialty Surgery, Department of Obstetrics and Gynecology, Columbia University Irving Medical Center/New York-Presbyterian Hospital.

Dr. Advincula is Levine Family Professor of Women's Health; Vice-Chair, Department of Obstetrics \& Gynecology; Chief of Gynecology, Sloane Hospital for Women; and Medical Director, Mary \& Michael Jaharis Simulation Center, Columbia University Irving Medical Center, New York-Presbyterian Hospital. He serves on the OBG MANAGEMENT Board of Editors.

Dr. Advincula reports being a consultant to Abbvie, Baxter, ConMed, CooperSurgical, Eximis Surgical, Intuitive Surgical, and Titan Medical and receiving royalties from CooperSurgical. The other authors report no financial relationships relevant to this video. 